Hydrogeology Journal, 2005, 13 (5-6), 665-674. DOI 10.1007/s10040-005-0439-4

\title{
Validation of a methodology for assessing intrinsic groundwater pollution vulnerability using a national nitrate database
}

Holman, I.P., Palmer, R.C., Bellamy, P.H. and Hollis, J.M.

I.P. Holman

Institute of Water and Environment, Cranfield University, Silsoe, Bedford, MK45 4DT, UK

Tel: $\quad+44(0) 1525863252$

Fax: $\quad+44(0) 152586334$

Email i.holman@cranfield.ac.uk

R.C. Palmer, Bellamy, P.H and Hollis, J.M

National Soil Resources Institute, Cranfield University, Silsoe, Bedford, MK45 4DT, UK

\begin{abstract}
The importance of groundwater for potable supply, and the many sources of anthropogenic contamination, has led to the development of intrinsic groundwater pollution vulnerability mapping. An Analysis of Co-Variance and Analysis of Variance are used to validate the extensively applied UK methodology, based upon nitrate concentrations from 1108 boreholes throughout England and Wales. These largely confirm the current aquifer and soil-leaching potential classifications and demonstrate the benefits of combining soil and low permeability drift information.
\end{abstract}


European legislation such as the Water Framework Directive will require more dynamic assessments of pollutant risk to groundwater. These results demonstrate that a number of improvements are required to future intrinsic groundwater pollution vulnerability methodologies. The vertical succession of geological units must be included, so that nonaquifers can be zoned in the same way as aquifers for water supply purposes, while at the same time recognising their role in influencing the quality of groundwater in deeper aquifers. Classifications within intrinsic vulnerability methodologies should be based upon defined diagnostic properties rather than expert judgement. Finally the incorporation into groundwater vulnerability methodologies of preferential flow in relation to geological formations, soil type and land management practices represents a significant, but important, future challenge.

Keywords Groundwater protection, Groundwater pollution vulnerability, Preferential flow, Nitrate, Soil-leaching potential.

\section{Introduction}

Groundwater is an important source of drinking water in many countries. Nevertheless, groundwater quality is universally under threat and requires protection from a variety of point and non-point source (NPS) pollutants. In recognition of the importance of groundwater to society, many countries have produced methodologies that assess the vulnerability of groundwater to NPS pollutants.

Foster (1987) defined "aquifer pollution vulnerability" as a measure of the protection afforded to an aquifer's saturated zone from vertical pollutant migration and the pollutant attenuation capacity of the overlying strata and soils. Groundwater vulnerability maps, which zone the 
land surface according to the likelihood of surface-derived pollutants reaching groundwater, have been developed using a variety of ranking or scoring systems to produce qualitative (e.g. Robins et al. 1994; Geological Survey of Ireland 1999) or semi-qualitative (Secunda et al. 1998; Fritch et al. 2000) output. Typically based on existing datasets, they represent an initial screening to help early decision making by environmental managers, rather than providing an alternative to site-specific investigations.

However, there has been little work carried out to test the validity of most groundwater vulnerability methodologies (Vrba and Zaporozec 1994). The principal exception is the DRASTIC model (Aller et al. 1987), which has been demonstrated to give a good relationship with nitrate concentrations in groundwater (Navulur and Engel 1998; Secunda et al. 1998) but a poor relationship with pesticide detections (Wade et al. 1998).

This paper describes a national scale validation of the groundwater vulnerability methodology of England and Wales (Environment Agency 1998) which was developed for use with preexisting datasets. The qualitative assessment concepts used in the methodology (Palmer et al. 1995) have also been applied, slightly adapted to suit local soil and/or geological conditions, in Lithuania (Holman et al. 2000) and The Philippines (Holman and Palmer 1998, 1999). Variations of the soil component of the methodology (the soil-leaching potential) are also used in Decision Support Systems for minimising agrochemical pollution (Brown et al. 2003; Holman et al. 2004). The aims of this paper are to assess whether an intrinsic vulnerability methodology based on pre-existing national datasets can be successfully validated and to highlight any wider implications for groundwater vulnerability mapping. 


\section{The UK groundwater vulnerability methodology}

The development of the UK groundwater vulnerability concept and subsequent methodology is described by Robins et al. (1994). The methodology is unique in the way it integrates soil and geological properties, together with hydrogeology (Palmer et al. 1995), through the assessment of the properties of the unsaturated soil-drift-rock column. The main factors in the assessment are:

- The permeability of aquifer material within the unsaturated zone;

- The presence of low permeability surficial drift deposits;

- The presence and nature of overlying soil, as described by the Soil-leaching Potential;

A three-fold aquifer classification is used, based on classifying units down to the first solid geological formation. Whilst all groundwaters are afforded protection, regardless of whether, or how, they are currently used, it is convenient for strategic land use planning considerations to subdivide permeable strata into the categories of Major Aquifers and Minor Aquifers. Due to a greater propensity for fracturing and rapid fissure flow, Major Aquifers (such as the Chalk and Sherwood Sandstone Group) have less capacity for attenuating contaminated recharge entering at their surface than Minor Aquifers, such as the Carboniferous Coal Measures and glaciofluvial sand and gravel deposits (Environment Agency 1998). Most groundwater sources used for large-scale public water supply (PWS) are abstracted from Major Aquifers. Low permeability strata (e.g. Mercia Mudstone Group) are classified as Non-Aquifers, even though sufficient water supplies for isolated dwellings are locally available. Geological units occurring beneath the uppermost solid strata are never considered in the aquifer classification, even if they are Major or Minor Aquifers. 
Low permeability surface drift deposits (such as boulder clay, clay-with-flints, estuarine alluvium) may afford some protection from potential pollutants. Their presence is depicted on the maps only where they overlie areas classified as Minor or Major Aquifers. In the absence of nationally available data on drift characteristics, 'low permeability drift' is generally not sub-divided according to its thickness or properties (although minor exceptions to this are described in Palmer et al. 1995). In other words, $5 \mathrm{~m}$ of 'low permeability drift' with a hydraulic conductivity of $0.01 \mathrm{~m} / \mathrm{d}$ is treated the same as $50 \mathrm{~m}$ with a hydraulic conductivity of $0.000001 \mathrm{~m} / \mathrm{d}$. .

The Soil-Leaching Potential classification assesses the degree of protection afforded by the soil layers to groundwater and is therefore only depicted on areas of Minor and Major Aquifers. It is based on those physical and chemical soil properties that can affect permeability and chemical attenuation, such as soil thickness, parent material, texture, organic carbon content, and the depth, duration and cause of waterlogging.

The soil-leaching potential classification has been validated at the site-specific scale using large $(70 \mathrm{~cm}$ diameter) undisturbed soil lysimeters to measure the leaching of pesticide and bromide under a range of rainfall regimes (Brown et al. 2000). The use of lysimeter studies to validate a methodology which is designed to depict vulnerability at a larger scale is supported by studies comparing lysimeters and plot results (Fent et al. 1999) and lysimeter and field results (Jene 1998). A limited validation exercise in Lithuania, based on groundwater samples from 212 sites, demonstrated a link between soil-leaching potential and underlying nitrate concentrations in shallow groundwater (Holman et al. 2000). Nevertheless in order to demonstrate the validity of this widely applied methodology it is necessary to show that it can 
cope with the heterogeneity encountered in real systems at the regional scale for which this methodology was intended.

\section{Methodology}

Input data

Nitrate represents the most widespread non-point source pollutant of groundwater in the UK. The control of nitrate leaching has been, and will continue to be, an important legislative requirement, with European Union instruments such as the Nitrates Directive (91/676/EEC) (CEC, 1991) and Water Framework Directive (2000/60/EC; Chave 2001) requiring limits on nitrate concentrations in groundwater. The Environment Agency, the regulatory body for maintaining or improving the quality of waters in England and Wales, has developed a national database of nitrate concentrations (expressed as $\mathrm{mg} / \mathrm{L} \mathrm{NO}_{3}-\mathrm{N}$ ) in groundwater, in accordance with the Nitrate Directive. This is based primarily from analyses from public water supply (PWS) boreholes throughout all the regions of England and Wales.

The database (version 2.0), which contains between 1 and 3065 measurements of nitrate concentration from each of 1108 boreholes as shown in Fig. 1, has been used as the validation dataset in this study. The mean nitrate concentrations at each borehole were calculated and shown to be normally distributed (Fig 2), allowing conventional parametric statistical techniques to be used.

Two forms of independent variables were used to investigate the variation in the mean nitrate concentrations (which represent the continuous dependent variable):

- Categorical: all from the published groundwater vulnerability maps:

Aquifer class- Major, Minor and Non-Aquifer 
Presence of low permeability drift at the surface- Yes / No

Soil-leaching potential- High, Intermediate and Low.

- Continuous:

Potential soil moisture deficit (PSMD)- a $5 \mathrm{~km}$ x $5 \mathrm{~km}$ gridded dataset which gives a measure of the dryness of the climate (Jones and Thomasson 1985), which affects nitrogen mineralization and soil cracking;

Excess Winter Rainfall (XWR)- a $5 \mathrm{~km}$ x $5 \mathrm{~km}$ gridded dataset which gives a measure of the excess of rainfall over evapotranspiration in the winter and hence an indication of the proportion of rainfall available for recharge and solute movement (Smith 1976); Livestock nitrogen loading to land- a $5 \mathrm{~km}$ x $5 \mathrm{~km}$ gridded dataset calculated by combining livestock numbers (total dairy cows, total pigs, etc.), derived from government agricultural census data for 1988 with default values for excreted nitrogen per head of livestock (IPCC 1997);

Crop nitrogen loading- a $5 \mathrm{~km}$ x $5 \mathrm{~km}$ gridded dataset calculated by combining arable and horticultural cropping statistics, derived from government agricultural census data for 1988 with typical nitrogen application rates (MAFF 1994).

While Tesoriero and Voss (1997) found that depth to groundwater and / or depth to the screened interval in a well significantly influenced the probability of elevated nitrate levels in groundwater, there is insufficient information available across UK aquifers to incorporate such factors in this analysis. In addition to nitrogen loading, the nitrogen pool available for leaching can be affected by land management practices such as ploughing (which increases the mineralization opportunities- Vinten et al. 2002; Di 2002) and rotations (Allingham et al. 2002). However, there is a lack of national data on land management practices which 
precludes their inclusion in the analysis, although it is expected that the distribution and proportion of ploughed land will be related to the crop nitrogen loading dataset.

\section{Approach}

At each borehole location, defined by the grid reference within the nitrate database, the relevant soil, drift and aquifer classifications were extracted from the digital groundwater vulnerability maps using a point-in-polygon procedure within an ArcView GIS (Burrough and McDonnell 1998). The same procedure was used to determine the continuous variable values for each site.

Two statistical analyses were performed to establish whether the components of the intrinsic groundwater vulnerability methodology are statistically significant in explaining the variation in mean groundwater nitrate concentration:

1. Analysis of Variance (ANOVA). ANOVA is a statistical technique to test for significant differences between means by comparing variances (Snedecor and Cochran 1989). It tests for whether the variation within the mean value of groundwater nitrate concentration for a categorical variable class is significantly less than the variation between the mean values of the different categorical variable classes.

In this study, for this analysis, the boreholes nominally located within Non-Aquifers were removed (reducing the dataset to 930 boreholes), as soil-leaching potential and drift are not defined in these areas. The ANOVA investigated whether the soil-leaching potential, drift and aquifer type (Major and Minor Aquifers only) explain a significant proportion of the variability in the mean nitrate concentration at the boreholes. 
2. Analysis of Co-Variance (ANCOVA) is a technique that combines the features of Analysis of Variance and linear regression and allows for the effect of continuous variables on the dependent variable (mean nitrate concentration) whilst investigating the effect of the different categorical variables.

The covariates (continuous variables) were not included in the initial (ANOVA) analysis as there was insufficient data available to give a reasonable spread in the continuous variables and sufficient number of samples in some categorical variable classes (e.g. of aquifer type, soil-leaching potential etc).

In this study the ANCOVA was used to investigate the effect of the aquifer class (including Non-Aquifer) on the mean nitrate concentration at the boreholes, after allowing for the effects of PSMD, XWR and crop and livestock nitrogen loadings which are expected to be related to the mean nitrate concentration. It was also possible to investigate the significance of these relationships. When performing ANCOVA it is important that the covariates ( PSMD, XWR, crop and livestock nitrogen loadings) are independent of each other. In this study the four covariates were obtained from different data sources and at different scales so it is anticipated that any correlation between them is minimal

In all the analyses presented here any differences in means are 'significant' when the probability (p) (under the null hypothesis that there are no significant differences between the mean nitrate concentrations of the categorical variable classes) of that difference occurring by chance is less than 0.05 . 


\section{Results}

\section{Analysis of variance (ANOVA) for boreholes in areas of Major and Minor Aquifer}

The results of the ANOVA are given in Table 1. Of the three categorical variables on the groundwater vulnerability map (aquifer class, low permeability drift and soil-leaching potential), the only variable for which the mean nitrate concentrations are significantly different is soil-leaching potential. The mean nitrate concentrations for boreholes through low leaching potential soils $(30.3 \mathrm{mg} / \mathrm{L})$ are significantly lower than for soils with either high (37.0 mg/L) or intermediate (35.2 mg/L) leaching potential (Fig. 3).

The analytical error for nitrate measurement in water is typically less than $1 \mathrm{mg} / \mathrm{L} \mathrm{NO}_{3}-\mathrm{N}$ (BSI 1999), although it would be anticipated that the analytical error would be randomly distributed across the boreholes. Notwithstanding whether the analytical error confounds the effect being looked at or not, the differences are in all cases greater than the analytical error.

In addition to the significant differences associated with soil-leaching potential, there are significant interactions between the effects of soil-leaching potential, drift and aquifer class on mean nitrate concentration, the key ones of which are discussed below. However, an inevitable problem in any spatially extensive groundwater vulnerability mapping methodology which involves overlaying datasets of different scales, sources and interpretation are mismatches. Although the following Figures show all combinations of aquifer, drift and soil from the maps, there are certain combinations of drift and soil which represent differences in interpretation. The issue of mismatches is discussed later in the paper, but the combinations of Low soil-leaching potential without low permeability drift and High soil-leaching potential with low permeability drift represent fundamental mismatches in 
interpretation between the geological mapping and the soil mapping, for which a significant relationship cannot be expected. The results described below focus on those relationships that represent true comparisons, rather than describing those which are the result of data mismatches.

\section{Interaction between soil-leaching potential and low permeability drift cover}

- Boreholes located in areas of Low leaching potential soils over low permeability drift cover (which are expected to provide maximum protection to underlying groundwater) have a significantly lower mean nitrate concentration $(25.3 \mathrm{mg} / \mathrm{L})$ than with any other combination (Fig. 4);

- In areas without low permeability drift cover, boreholes in areas with High leaching potential soils have a significantly higher mean nitrate concentration $(36.8 \mathrm{mg} / \mathrm{L})$ than boreholes in areas with Intermediate leaching potential soils $(33.2 \mathrm{mg} / \mathrm{L})$.

However, boreholes in areas of Intermediate leaching potential soils developed in low permeability drift have a significantly higher mean nitrate concentration $(45.8 \mathrm{mg} / \mathrm{L})$ compared to those in areas of either Intermediate $(33.2 \mathrm{mg} / \mathrm{L})$ or High $(36.8 \mathrm{mg} / \mathrm{L})$ leaching potential soils developed in permeable material. This does not support the current vulnerability classification.

\section{Interaction between aquifer class and soil-leaching potential}

In areas of low leaching potential soils, there is no significant difference in mean nitrate concentration between Major or Minor Aquifers. However, in areas of more permeable soils the mean nitrate concentrations in the more permeable Major Aquifers overlain by High and Intermediate leaching potential soils (38.5 and $38.7 \mathrm{mg} / \mathrm{L}$, respectively) are significantly 
higher than in Minor Aquifers overlain by the same leaching potential classes (33.0 and 26.9 $\mathrm{mg} / \mathrm{L}$, respectively).

Interaction between aquifer class, soil-leaching potential and low permeability drift cover The inclusion of aquifer class in Fig. 5 reinforces the significant relationships previously observed between soil-leaching potential and presence of low permeability drift, ignoring the mismatches previously identified.

\section{Analysis of Covariance (ANCOVA) for all boreholes}

Table 2 shows the results of the ANCOVA. Of the covariates only PSMD and livestock loading explained a significant amount of variation. After allowing for the influence of the covariates on nitrate concentrations, aquifer class has a significant effect on mean nitrate concentrations. All comparisons between the mean nitrate concentrations for the different aquifer classes in Fig. 6 are significant. The mean value for Major Aquifers was 37.9 mg/L, for Minor Aquifers $30.5 \mathrm{mg} / \mathrm{L}$ and Non-Aquifers $33.8 \mathrm{mg} / \mathrm{L}$.

\section{Discussion}

The results of the ANOVA have largely supported the intrinsic groundwater vulnerability methodology for use in national and regional applications. However, the analysis has highlighted a number of limitations which are pertinent to the application of most intrinsic vulnerability methodologies.

\section{Depiction of aquifer classes and their vertical sequence}

In order to provide unambiguous maps that can be used by non-specialists, simplification of the natural complexity had to be incorporated in the UK vulnerability maps. The aquifer 
classification therefore either shows the uppermost solid geological formation (if it is classified as an aquifer) or, where this is classified as a Non-Aquifer, the map shows the uppermost permeable drift unit. Where low permeability drift overlies a Non-Aquifer, this is shown as a Non-Aquifer, even where the Non-Aquifer may overly a Major or Minor Aquifer.

The sub-division of geological formations into Major, Minor and Non-Aquifers is largely supported by the analysis. The highly significant difference between the mean nitrate concentration in Major Aquifer boreholes compared to those in Minor Aquifers is consistent with the higher permeability in Major Aquifers and the potential for rapid transport of recharge (and solutes) to the water table. The difference may also represent the effects of greater dilution within the more heterogeneous and dispersive groundwater systems (Pang et al. 2000) of Minor Aquifers.

The treatment of areas classified on the maps as Non-Aquifers is more complex, because of their potential dual roles in water resource protection and supply. Although the boreholes used in this study within areas designated as Non-Aquifers will be abstracting from underlying aquifers, no distinction is made on the maps between such areas and areas of generally low permeability (e.g. the areas of Lower Palaeozoic and Precambrian rocks in northwest England and Wales).

In a hydrogeological setting characterised by a Non-Aquifer overlying an important aquifer, but which is depicted on the vulnerability maps as a Non-Aquifer, the overlying Non-Aquifer can influence groundwater quality in the underlying aquifers. The lower mean nitrate concentrations in the boreholes penetrating Non-Aquifers compared to those depicted as Major Aquifers may suggest that the overlying Non-Aquifer is either limiting the downward 
movement of nitrate-rich recharge to the deep groundwater or providing a suitable environment for denitrification (Feast et al. 1998), or that partial denitrification is occurring in the confined portion of the aquifer (Moncaster et al. 2000). That the mean nitrate concentration is greater than that in Minor Aquifers suggests that in many cases these processes are incomplete, that some of the underlying aquifers are unconfined or that nitraterich unconfined groundwater is being drawn into confined or semi-confined portions of the aquifer as a result of high pumping rates.

The Water Framework Directive requires the input of pollutants to all groundwater to be prevented or limited, regardless of whether they are used for public water supply. There are many small groundwater sources used for private supply in Non-Aquifer deposits which offer an important social and economic asset to isolated rural communities (Robins 1999). They are currently not protected by the zoning on the maps.

The next generation of groundwater protection tools needs to indicate the vertical succession of units (for example as depicted on CEC 1982) so that Non-Aquifers can be zoned in the same way as Minor and Major Aquifers for water supply purposes, while at the same time recognising their role in influencing the quality of groundwater in deeper aquifers.

\section{Mismatches arising from the map scales used and interpretation of input data}

In applying groundwater vulnerability methodologies, the usual procedure is to use the best available data, rather than to use data at the smallest common map scale. For example, within the UK groundwater vulnerability maps, the scale of the geological information ranges from $1: 10,000$ to $1: 250,000$ (mostly at 1:50,000) while that of the soil information ranges from 
1:25,000 to 1:250,000 (mostly at 1:250,000 scale), depending upon location. All are depicted on the published map at 1:100,000 scale with simplification and amalgamation where necessary. As a result, there are inevitable discrepancies in interpreting the groundwater vulnerability maps between the geological and soil data (Palmer et al. 1995). About $9 \%$ of the boreholes examined in the ANOVA (i.e. in areas of Major or Minor Aquifers only) were in locations in which the soil parent material at $1 \mathrm{~m}$ depth suggest a mismatch with the geological data. For example, 49 boreholes are in locations where the map shows soils of Low leaching potential, which by definition must have low permeability subsoils, overlying an aquifer without a covering of low permeability drift and 34 boreholes are in locations where the map shows permeable soils of High leaching potential and a covering of low permeability drift.

It is important that users of regional vulnerability maps are aware of the inevitable use of mapping input data at different scales, the combinations of input data which represent mismatches and the procedures to employ when this occurs. Without this information (e.g. Palmer et al. 1995), users may inadvertently make incorrect decisions when using such maps.

\section{Pollutant pathways through the soil / drift column}

Ignoring the soil-drift combinations representing soil/geology mismatches as described above (and in Palmer et al. 1995), Fig. 4 shows that the mean nitrate concentration, for the four most probable combinations of presence/ absence of low permeability drift and soil-leaching potential, increases in the following order:

- Presence of low permeability drift with Low soil-leaching potential

- Absence of low permeability drift with Intermediate soil-leaching potential 
- Absence of low permeability drift with High soil-leaching potential

- Presence of low permeability drift with Intermediate soil-leaching potential

The first three combinations, which are in the anticipated order, are all significantly different. This supports the view that the boreholes in the best protected areas will generally be located where Low leaching potential soils overlie low permeability drift deposits and that boreholes located in areas where High leaching potential soils overlie permeable material (which will characterise most areas of shallow or sandy soils over aquifer outcrop) are afforded much less protection.

It could be argued that the latter results might be due to there being more ploughed land or higher nitrate loadings on thick, well drained soils which characterise many of the areas of intermediate or high leaching potential overlying aquifers. For example, recommended fertiliser application rates for cereals are typically greater on sandy soils than clay soils (MAFF 1994). However, that a similar relationship is observed between aquifer class and mean nitrate concentration in both the ANOVA and ANCOVA, indicates that intrinsic properties can have a demonstrable effect on mean nitrate concentration, having allowed for the effects of the continuous variables. This is supported by the analysis of Loveland (1998) which showed that soil type alone is a poor predictor - nationally or regionally - of farming practice and vice versa.

Although the first three combinations above are in the anticipated order, the results for Intermediate leaching potential soils in low permeability drift suggest that there is an aspect of nitrate movement through these areas which presently is not adequately catered for in the current groundwater vulnerability methodology. 
As a generalization, the typical resolution of the drift geological mapping data (1:50,000 scale) used in the production of the groundwater vulnerability maps is better than the soil information (1:250,000 scale). Nevertheless the ANOVA has suggested that soil information on its own is a better determinant of mean nitrate concentration than drift geology as currently mapped on the groundwater vulnerability maps. In the production of the groundwater vulnerability maps, each soil type is classified into a soil-leaching potential class based upon defined diagnostic properties (Hodgson 1997; Avery 1980) which influence water and solute movement, measured or observed in the field at the time of the original soil mapping. This allows different soil types developed in the same drift type to be assigned to different soilleaching potential classes based upon observations and measurements. However, in the case of the geological information each drift deposit is classified by expert judgement wholly into either low permeability drift or permeable drift. Swartz et al. (2003) demonstrate that the assumption that till deposits are sufficiently homogeneous to be represented by a single permeability classification is an oversimplification.

It is possible therefore that the 'low permeability' drift deposits beneath Intermediate leaching potential soils are different from those beneath Low leaching potential soils, as indicated by the evidence of relatively short duration of soil wetness in Intermediate leaching potential soils compared to the prolonged waterlogging of Low leaching potential soils. A number of mechanisms may potentially increase the downward flux of water and solutes through these permeable so-called 'low permeability' drift deposits. Vertical gravel-filled dykes, as found in till in Ireland (Rijsdijk 1999), which are interpreted as the infillings of fractures can provide very permeable routes through otherwise impermeable layers. Weathered Quaternary aquitards (till, glaciolacustrine, and loess deposits) in North America were found to have 
greatly reduced ability to attenuate nitrate and pesticides, compared to unweathered Quaternary aquitards (Rodvang and Simpkins, 2001). This was ascribed to reduced sulfur and sorptive/labile organic carbon, and a higher bulk hydraulic conductivity due to fractures. Finally, macropore / preferential / dual porosity flow in till can also occur, the importance of which has been recognised for general contaminant transport (Scanlon et al. 2002). For example, Jorgensen and Fredericia (1992) observed dual porosity in the upper $10 \mathrm{~m}$ of a fractured clayey till, and rapid leaching in the macropore structure. Clay-rich Intermediate leaching potential soils, developed in the 'same' parent material as Low leaching potential soils, would be anticipated to be more prone to by-pass flow arising from increased cracking as they will start to dry out more quickly in summer than the Low leaching potential soils and attain greater soil moisture deficits so that maximum cracking will be achieved earlier, more often and for longer periods. This analysis has shown that the presence or absence of low permeability drift as a measure of the protection afforded to groundwater by drift deposits needs improving. In the absence of nationally available spatial data on the hydraulic properties of drift, it is considered that further investigation of the integration of soil and geological information as an indicator of drift properties is merited.

Although the importance of preferential flow to leaching of bromide (Aderhold and Nordmeyer 1995), pesticides (Brown et al. 2000) and nitrate (Bergström and Johansson 1991; Stout et al. 1998) through soil been demonstrated in lysimeter studies, its incorporation into groundwater vulnerability methodologies is limited (e.g DRASTIC; Holman et al. 2004). No attempts to date have been made to incorporate preferential flow through non-karstified geological material in any groundwater vulnerability methodology. 
Preferential flow in cracking or shrinking clay soils is relatively easily incorporated, as in DRASTIC, but it occurs in geological formations and in a much wider variety of soil types (Brown et al. 2000) and can be altered by land management practices (Mori et al. 1999; Hangen et al. 2002). The incorporation of these somewhat less predictable conduits of preferential flow into groundwater vulnerability methodologies represents a significant, but important, challenge.

\section{Pollutant loading}

The current groundwater pollution vulnerability assessment for the UK is based on classification of intrinsic properties of combined soil and aquifer layers. Validation of these types of classification using a single pollutant such as nitrate is problematical because any validation introduces factors that are temporally, as well as spatially, variable. Thus the presence of nitrate in groundwater will depend on the amount and timing of surface loadings, soil nitrate levels particularly in the late autumn (Di and Cameron 2002) and their relationships to climatic factors such as rainfall and PSMD. For example, relatively high rainfall to dilute surplus nutrients, combined with year-round moist soils (low PSMD) with an active bacterial population, can ensure generally low nitrate concentrations (Robins 1998).

To better represent the relationships controlling nitrate (and other pollutants) in groundwater, the results of this validation suggests that the next generation of groundwater protection tools should focus more on risk-based approaches. Dynamic factors such as surface pollutant loading and climatically or biologically dependent degradation potential should be integrated with intrinsic characteristics such as soil-leaching potential and aquifer hydrogeology (e.g. Holman et al. 2004; Lovett et al. 2001). In developing such national scale risk-based 
approaches, techniques based on physically-based relationships or metamodels may be preferable, as they can account for system non-linearities such as between recharge volume and pollutant concentration (e.g. Lord and Anthony 2000; Holman et al. 2004).

\section{Conclusions}

The qualitative assessment concepts used in the intrinsic groundwater pollution vulnerability methodology for England and Wales have been widely applied, both in the UK and overseas. The methodology, based on combining existing spatial datasets of soil and geological properties, is largely supported by a validation using a national database of nitrate concentrations from 1107 boreholes throughout England and Wales. However, the analysis has highlighted a number of limitations which are shared by most intrinsic vulnerability methodologies.

The Water Framework Directive requires all groundwaters in the European Union to be protected from pollution, including those in geological materials currently designated as NonAquifers. Groundwater protection tools will need to indicate the vertical succession of geological units, so that Non-Aquifers can be zoned in the same way as Minor and Major Aquifers for water supply purposes, while at the same time recognising their role in influencing the quality of groundwater in deeper aquifers.

The high mean nitrate concentrations associated with Intermediate leaching potential soils in low permeability drift suggest that there is an aspect of nitrate movement which presently is not currently adequately catered for. An Analysis of Variance has suggested that soil information is a better determinant of mean nitrate concentration than drift geology as 
currently mapped on the groundwater vulnerability maps. It is considered that this arises because the soil classification is based upon properties measured or observed in the field, rather than by the expert judgement currently used to assess the influence of drift geology. The development of intrinsic vulnerability methodologies based upon defined diagnostic properties for both soil and drift, and the incorporation of preferential flow characteristics of geological formations, soil types and land management practices represent significant, but important, future challenges for groundwater vulnerability methodologies.

Although the intrinsic vulnerability classification has been demonstrated to be statistically significant in explaining the variation in mean nitrate concentrations, the importance of pollutant loading cannot be overlooked. Opportunities presented by legislation to update groundwater protection tools should be taken, in order to develop more dynamic assessments of pollutant risk to groundwater which incorporate these features.

\section{References}

Aderhold D, Nordmeyer H (1995). Leaching of herbicides in soil macropores as a possible reason for groundwater contamination. In: Walker A., Allen R., Bailey SW, Blair AM, Brown CD, Gunther P, Leake CR, Nicholls PH (eds.) Pesticide movement to water. BCPC Monograph No. 62. British Crop Protection Council, Surrey.

Aller L, Bennet T, Lehr JH, Petty RJ, Hackett, G (1987) DRASTIC: A standardised system for evaluating groundwater pollution potential using hydrogeological settings. EPA/600/287/035, US Environmental Protection Agency, Ada, Oklahoma 
Allingham KD, Cartwright R, Donaghy D, Conway JS, Goulding KWT, Jarvis SC (2002)

Nitrate leaching losses and their control in a mixed farm system in the Cotswold Hills, England. Soil Use and Management 18(4): 421-427

Avery BW (1980) Soil classification for England and Wales [Higher Categories]. Soil Survey Technical Monograph No 14, Harpenden.

Bergström LF, Johansson R (1991) Leaching of nitrate from monolith lysimeters of different types of agricultural soils. J. Env. Qual. 20: 801-807

Brown CD, Hollis JM, Bettinson RJ, Walker A. (2000). Leaching of pesticides and a bromide tracer through lysimeters from five contrasting soils. Pest Manag Sci 56: 83-93

Brown CD, Hart A, Lewis KA, Dubus IG (2003) p-EMA (I): simulating the environmental fate of pesticides for a farm-level risk assessment system. Agronomie 23(1): 67-74

BSI- British Standards Institute (1999) Water quality -Determination of dissolved fluoride, chloride, nitrite orthophosphate, bromide, nitrate and sulfate ions, using liquid chromatography of ions: [1]: Method for water with low contamination. EN ISO 10304-1

Burrough PA, McDonnell RA (1998) Principles of Geographic Information Systems. $2^{\text {nd }}$ edition, Oxford University Press, Oxford

CEC- Council of the European Communities (1982). Groundwater Resources of the European Community: Synthetical Report. Commission of the European Union, Directorate General for the Environment, consumer protection and nuclear safety. Th. Schafer GmbH, Hannover. 75pp.

CEC-Council of the European Communities (1991) Directive concerning the protection of waters against pollution caused by nitrates from agricultural sources (91/676/EEC).

Chave P (2001) The EU Water Framework Directive: An Introduction. IWA Publishing, London 
Di HJ, Cameron KC (2002) Nitrate leaching in temperate agroecosystems: sources, factors and mitigating strategies. Nutrient Cycling In Agroecosystems 64(3): 237-256

Environment Agency (1998) Policy and practice for the protection of groundwater. Stationary Office, London

Feast NA, Hiscock KM, Dennis PF, Andrews JN (1998) Nitrogen isotope hydrochemistry and denitrification within the Chalk aquifer system of north Norfolk, UK. J. Hydrol. 211(14): $233-252$

Fent G, Kubiak R Jene B (1999) Spatial distribution of ${ }^{14}$ C-Benazolin residues and two tracers in lysimeters in comparison to a field plot experiment. In: Del Re AAM, Brown C, Capri E, Errera G, Evans SP, Trevisan M (eds.) Human and environmental exposure to xenobiotics. Proc $11^{\text {th }}$ Symposium Pesticide Chemistry, Cremona, Italy.

Foster SSD (1987) Fundamental concepts in aquifer vulnerability, pollution risk and protection strategy. In: Vulnerability of soil and groundwater to pollutants, TNO Committee on Hydrological Research, The Hague, Proceedings and Information No. 38, pp 69-86

Fritch TG, McKnight CL, Yelderman JC, Arnold JG (2000) An aquifer vulnerability assessment of the Paluxy aquifer, central Texas, USA, using GIS and a modified DRASTIC approach. Environmental Management 25(3): 337-345

Geological Survey of Ireland (1999) Groundwater Protection Schemes. Report of the Department of Environment and Local Government, Environmental Protection Agency and the Geological Survey of Ireland

Hangen E, Buczko U, Bens O, Brunotte J, Huttl RF (2002) Infiltration patterns into two soils under conventional and conservation tillage: influence of the spatial distribution of plant root structures and soil animal activity. Soil \& Tillage Research ,63 (3-4): 181-186 
Hodgson JM (1997) Soil survey field handbook. Soil Survey Technical Monograph No 5, Silsoe.

Holman IP, Dubus IG, Hollis JM (2004) Using a linked soil model emulator and unsaturated zone leaching model to account for preferential flow when assessing the spatially distributed risk of pesticide leaching to groundwater in England and Wales. Science of the Total Environment; 318: 73-88

Holman IP, Palmer RC, Leonaviciute N (2000) Using soil and Quaternary geological information to assess the intrinsic groundwater vulnerability of shallow aquifers: an example from Lithuania. Hydrogeology Journal; 8: 636-645

Holman IP, Palmer RC (1998) Introducing multidisciplinary groundwater vulnerability mapping to the Philippines: a case study from Cebu City. J Geological Society of the Philippines 53 (3-4): 158-179

Holman IP, Palmer RC (1999) Groundwater protection incorporated into land use planning: a study from Cebu City, the Philippines. In Ellis, B. (ed). Impacts of Urban Growth on Surface Water and Groundwater Quality. Proc IUGG 99, Symposium HS5. IAHS Publ. no. 259 pp $125-132$

IPCC- Intergovernmental Panel on Climate Change (1997) Greenhouse gas emissions from agricultural soils. In: Houghton, J. T. (ed.) Greenhouse Gas Inventory Reference Manual.Revised 1996 IPCC Guidelines for National Greenhouse Gas Inventories. IPCC/OECD/IES. UK Meteorological Office, Bracknell, UK

Jene B (1998) Transport of bromide and benazolin in lysimeters and a field plot with grid suction bases in a sandy soil. PhD, University of Hohenheim, Germany Jones RJA, Thomasson AJ (1985) An Agroclimatic databank for England and Wales. Soil Survey Technical Monograph No. 16. Soil Survey, Harpenden 
Jorgensen Pr, Fredericia J (1992) Migration Of Nutrients, Pesticides And Heavy-Metals In Fractured Clayey Till. Geotechnique 42(1): 67-77

Lord EI, Anthony SG (2000) MAGPIE: A modelling framework for evaluating nitrate losses at national and catchment scales. Soil Use And Management 16: 167-174

Loveland PJ (ed.) (1998) The Impact of Farming Practices on Sustainable Use of Soil. Final Report for Department of Environment, Food and Rural Affairs project OC9403, London (unpublished)

Lovett A., Lake I., Hiscock K., Sunnenberg G., Foley, A., Evers S. Fletcher S (2001) Defining groundwater protection zones in England and Wales. In: Environment Agency (ed) Proc Protecting Groundwater conf, pp 249-260

MAFF- Ministry of Agriculture, Fisheries and Food (1994). Fertiliser recommendations for agricultural and horticultural crops. MAFF Reference Book 209. HMSO, London

Moncaster SJ, Bottrell SH, Tellam JH, Lloyd JW, Konhauser KO (2000) Migration and attenuation of agrochemical pollutants: insights from isotopic analysis of groundwater sulphate. J. Contaminant Hydrology 43(2): 147-163

Mori Y, Iwama K, Maruyama T, Mitsuno T (1999) Discriminating the influence of soil texture and management-induced changes in macropore flow using soft X-rays. Soil Science 164 (7): 467-482

Navulur KCS, Engel BA (1998) Groundwater vulnerability assessment to non-point source nitrate pollution on a regional scale using GIS. Trans ASAE 41(6): 1671-1678

Palmer RC, Holman IP, Lewis MA (1995) Guide to groundwater vulnerability mapping in England and Wales. HMSO, London

Pang L, Close ME, Watt JPC, Vincent KW (2000) Simulation of picloram, atrazine, and simazine leaching through two New Zealand soils and into groundwater using HYDRUS2D. J. Contaminant Hydrology 44: 19-46 
Rijsdijk KF, Owen G, Warren WP, McCarroll D, van der Meer JJM (1999) Clastic dykes in over-consolidated tills: evidence for subglacial hydrofracturing at Killiney Bay, eastern Ireland. Sedimentary Geology 129(1-2): 111-126

Robins NS (1998) The quality of shallow groundwaters in Northern Ireland. J. CIWEM 12 (3): 163-169

Robins NS (1999) Groundwater occurrence in the lower Palaeozoic and Precambrian rocks of the UK: Implications for source protection. J. CIWEM 13(6): 447-453

Robins NS, Adams B, Foster S, Palmer R (1994) Groundwater vulnerability mapping: the British perspective. Hydrogéologie 3:35-42

Rodvang SJ, Simpkins WW (2001) Agricultural contaminants in Quaternary aquitards: A review of occurrence and fate in North America. Hydrogeology J. 9(1): 44-59

Scanlon BR, Healy RW, Cook PG (2002). Choosing appropriate techniques for quantifying groundwater recharge. Hydrogeology J. 10(1), 18-39

Secunda S, Collin ML, Melloul AJ (1998) Groundwater vulnerability assessment using a composite model combining DRASTIC with extensive agricultural land use in Israel's Sharon region. J. Environmental Management 54(1): 39-57

Smith LP (1976) The agricultural climate of England and Wales. Technical Bulletin 35, HMSO, London

Snedecor GW, Cochran WG (1989). Statistical methods. Iowa State University Press, Ames Stout WL, Gburek WJ, Schnabel RR, Folmar GJ, Weaver SR (1998) Soil-climate effects on nitrate leaching from cattle excreta. J. Env. Qual. 27: 992-998

Swartz M, Misstear BDR, Daly D, Farrell ER (2003) Assessing subsoil permeability for groundwater vulnerability. Quart. J. Eng. Geol. 36: 173-184 
Tesoriero AJ, Voss FD (1997) Predicting the probability of elevated nitrate concentrations in the Puget Sound Basin: implications for aquifer susceptibility and vulnerability. Groundwater 35(6): 1029-1039

Vinten AJA, Ball BC, O'Sullivan MF, Henshall JK, Howard R, Wright F, Ritchie R (2002) The effects of cultivation method and timing, previous sward and fertilizer level on subsequent crop yields and nitrate leaching following cultivation of long-term grazed grass and grass-clover swards. J. Agric. Sci. 139(3): 245-256

Vrba J and Zaporozec A (1994) Guidebook on Mapping Groundwater Vulnerability. International Contributions to Hydrogeology No. 16, International Association of Hydrogeologists. Heise, Hanover

Wade HF, York AC, Morey AE, Padmore JM, Rudo KM (1998) The impact of pesticide use on groundwater in North Carolina. J. Env. Qual. 27 (5): 1018-1026

\section{Acknowledgements}

The authors gratefully acknowledge the Science Group of the Environment Agency who funded this work. The views expressed in this paper are the authors own, and do not necessary reflect those of the Environment Agency 
Table 1 Results of ANOVA of mean nitrate concentrations and the data layers within the groundwater vulnerability map

\begin{tabular}{|c|c|c|c|c|}
\hline Effect & $\begin{array}{l}\text { Degrees of } \\
\text { Freedom }\end{array}$ & $\begin{array}{l}\text { Mean } \\
\text { square }\end{array}$ & $\begin{array}{l}\text { Variance } \\
\text { ratio } \\
(\text { F-value })^{1}\end{array}$ & $\begin{array}{l}\text { Probability under } \\
\text { null hypothesis } \\
\text { (p) }\end{array}$ \\
\hline Drift & 1 & 849.1 & 3.7 & 0.055 \\
\hline Aquifer class & 1 & 337.3 & 1.5 & 0.226 \\
\hline SLP & 2 & 2386.7 & 10.4 & 0.000 \\
\hline $\begin{array}{l}\text { Interaction between Drift and } \\
\text { Aquifer class }\end{array}$ & 1 & 1703.3 & 7.4 & 0.007 \\
\hline $\begin{array}{l}\text { Interaction between SLP and } \\
\text { Drift }\end{array}$ & 2 & 1882.1 & 8.2 & 0.000 \\
\hline $\begin{array}{l}\text { Interaction between Aquifer } \\
\text { class and SLP }\end{array}$ & 2 & 1514.5 & 6.6 & 0.001 \\
\hline $\begin{array}{l}\text { Interaction between Aquifer } \\
\text { class, SLP and Drift }\end{array}$ & 2 & 1006.7 & 4.4 & 0.013 \\
\hline Error (or Residual) & 930 & 229.7 & & \\
\hline
\end{tabular}


Table 2 Results of an ANCOVA of mean nitrate concentrations

\begin{tabular}{|c|c|c|c|c|}
\hline Effect & $\begin{array}{l}\text { Degrees of } \\
\text { Freedom }\end{array}$ & $\begin{array}{l}\text { Mean } \\
\text { square }\end{array}$ & $\begin{array}{l}\text { Variance ratio } \\
(\text { F-value })^{1}\end{array}$ & $\begin{array}{l}\text { Probability under null } \\
\text { hypothesis (p) }\end{array}$ \\
\hline Aquifer class & 2 & 3655.2 & 14.5 & 0.000 \\
\hline PSMD (grass) & 1 & 3546.1 & 14.0 & 0.000 \\
\hline Excess Winter Rain & 1 & 570.2 & 2.3 & 0.133 \\
\hline Livestock loading & 1 & 8092.4 & 32.0 & 0.000 \\
\hline Crop loading & 1 & 195.8 & 0.8 & 0.379 \\
\hline Error & 1100 & 252.6 & & \\
\hline
\end{tabular}

${ }^{\mathrm{I}}$ The ratio of the between-group variance to the within-group variance 
Figure 1 Outline map of England and Wales showing distribution of boreholes in the Environment Agency's EC Nitrate Database v2.0

Figure 2 Distribution of mean nitrate concentration $\left(\mathrm{mg} / \mathrm{L} \mathrm{N}-\mathrm{NO}_{3}\right)$ in 1108 boreholes in the Environment Agency's EC Nitrate Database v2.0

Figure 3 Results of ANOVA showing the differences between the mean borehole nitrate concentrations for each soil-leaching potential (SLP) class

Figure 4 Results of ANOVA showing the differences between the mean borehole nitrate concentrations for the combination of soil-leaching potential class and presence or absence of low permeability drift

Figure 5 Results of ANOVA showing the differences between the mean borehole nitrate concentrations for the combinations of aquifer class, presence or absence of low permeability drift and soil-leaching potential class

Figure 6 Results of ANCOVA showing the differences between the mean borehole nitrate concentrations for the aquifer classes 


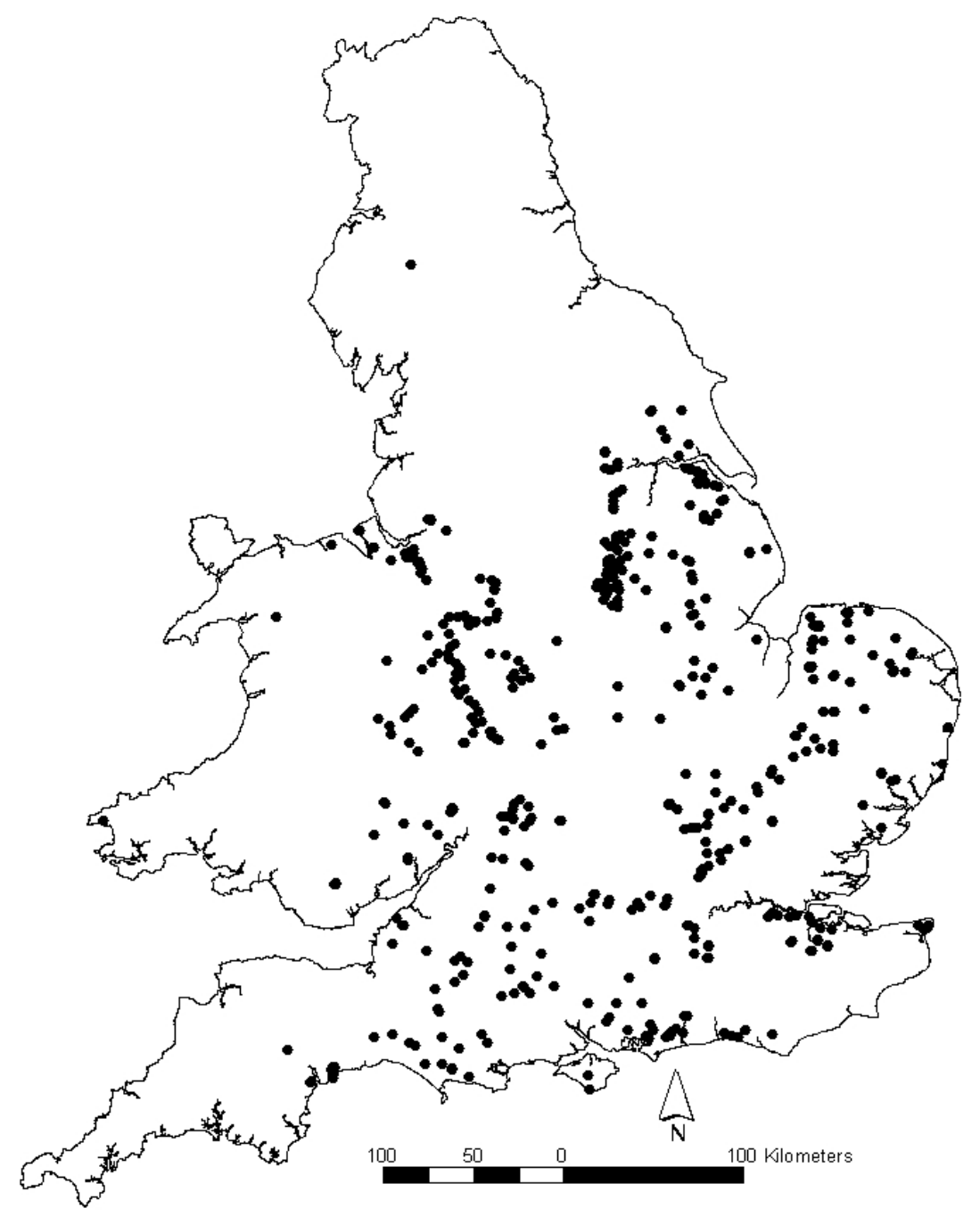

Figure 1 Outline map of England and Wales showing distribution of boreholes in the Environment Agency's EC Nitrate Database v2.0 


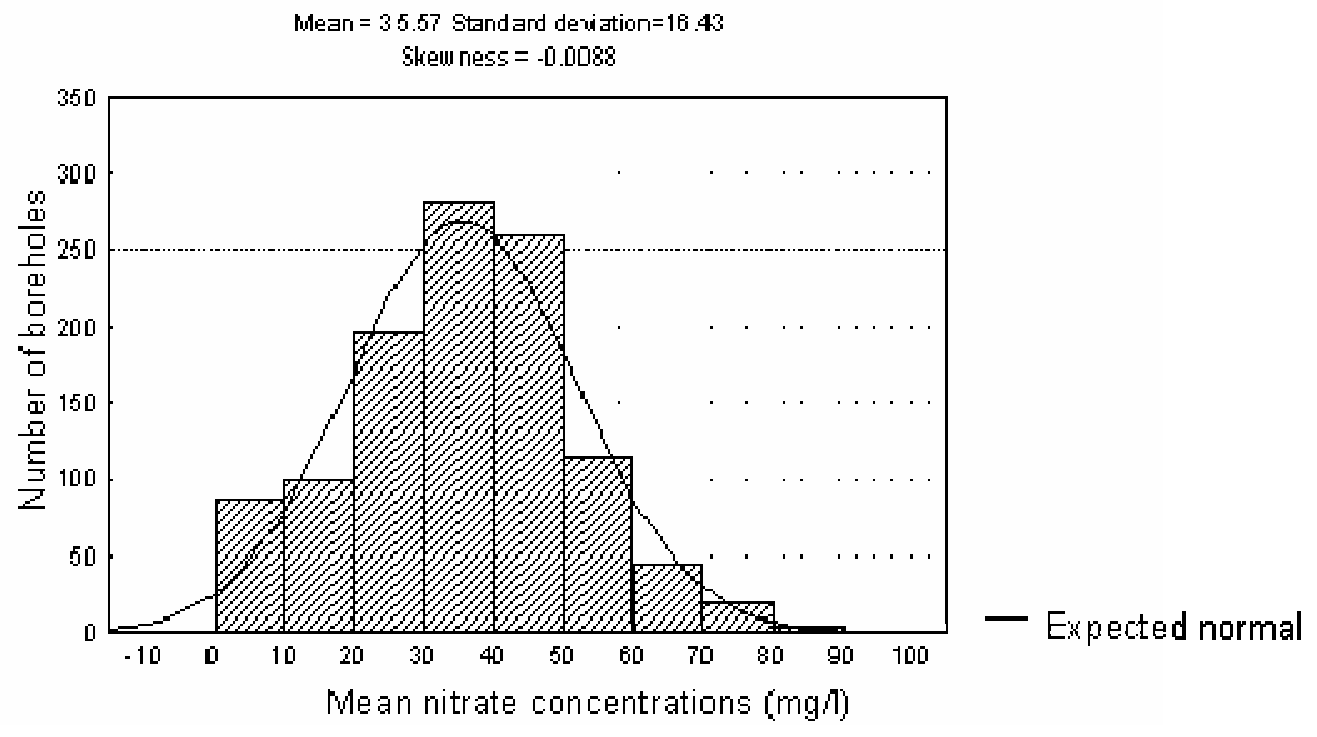

Figure 2 Distribution of mean nitrate concentration $\left(\mathrm{mg} / \mathrm{L} \mathrm{N}-\mathrm{NO}_{3}\right)$ in 1108 boreholes in the Environment Agency's EC Nitrate Database v2.0 


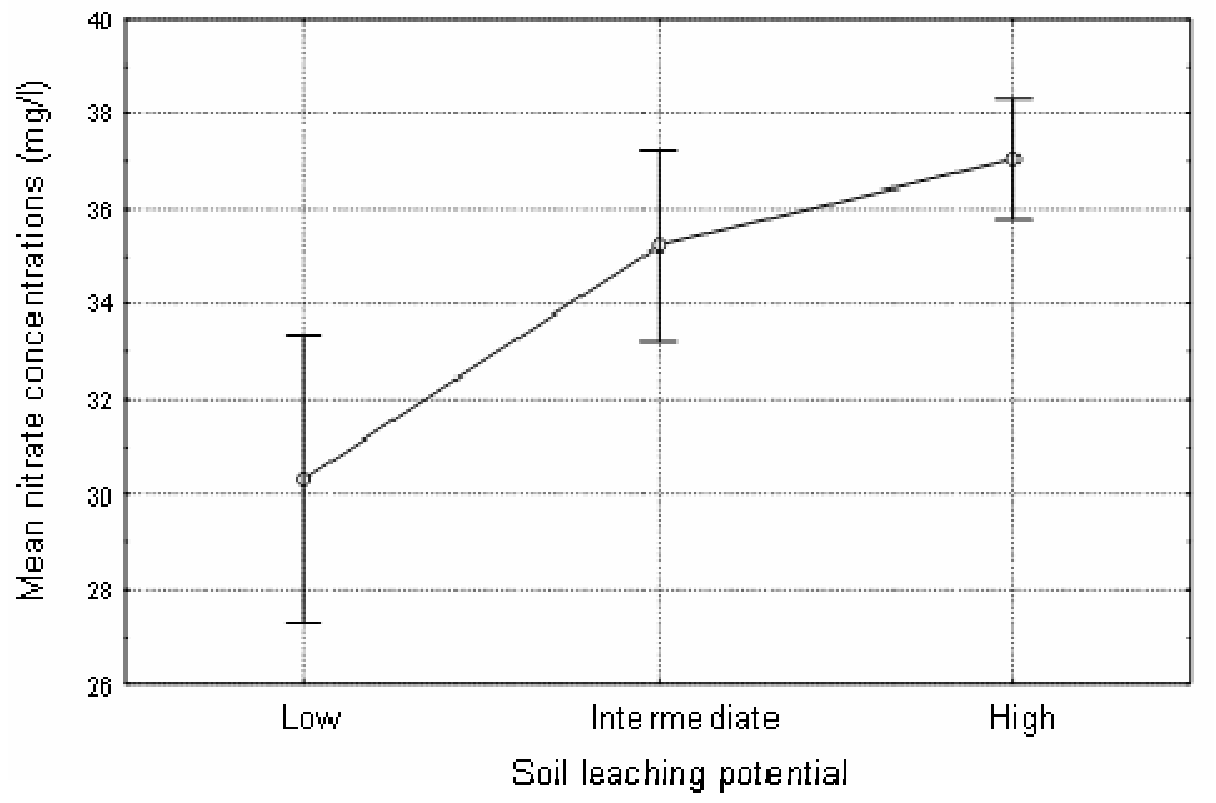

Figure 3 Results of ANOVA showing the differences between the mean borehole nitrate concentrations for each soil-leaching potential class 


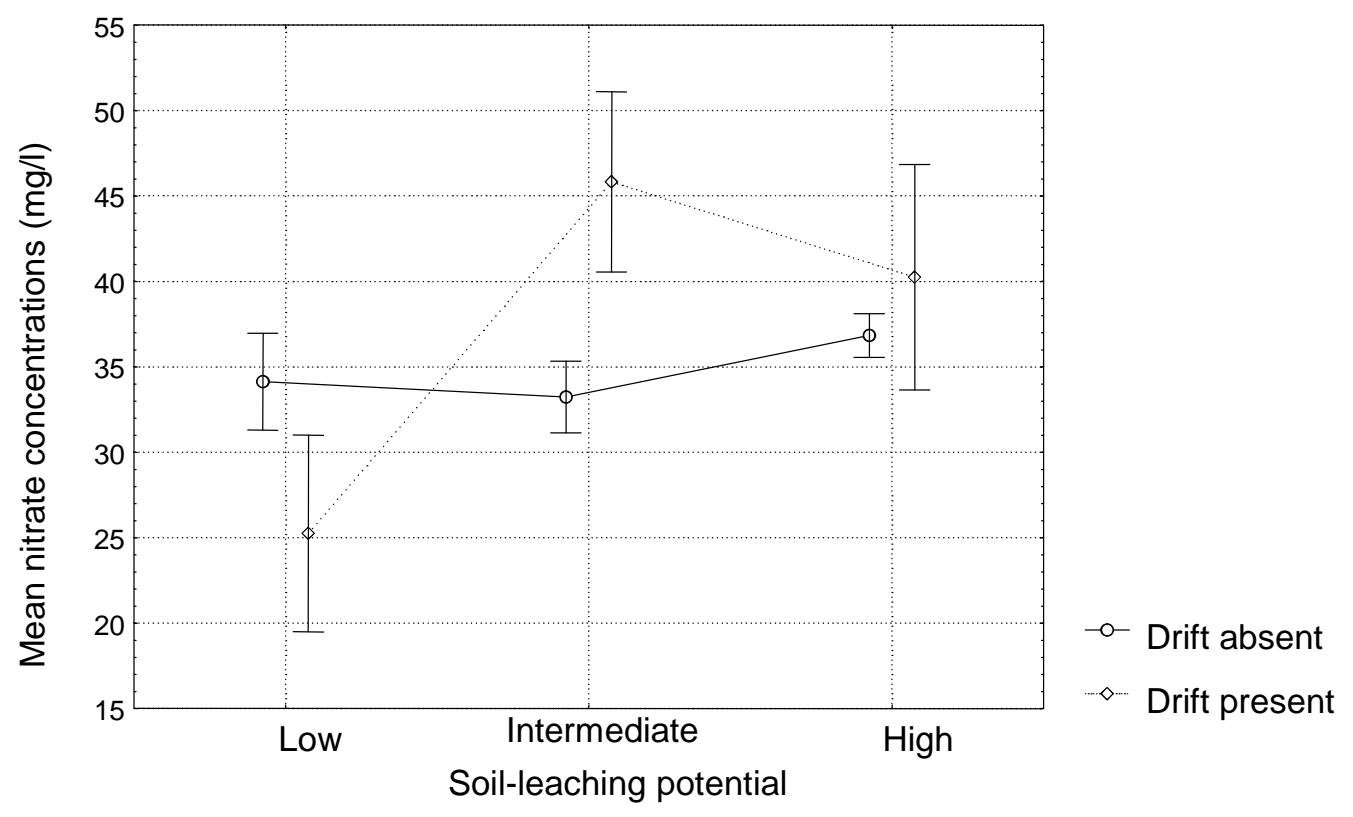

Figure 4 Results of ANOVA showing the differences between the mean borehole nitrate concentrations for the combination of soil-leaching potential class and presence or absence of low permeability drift 

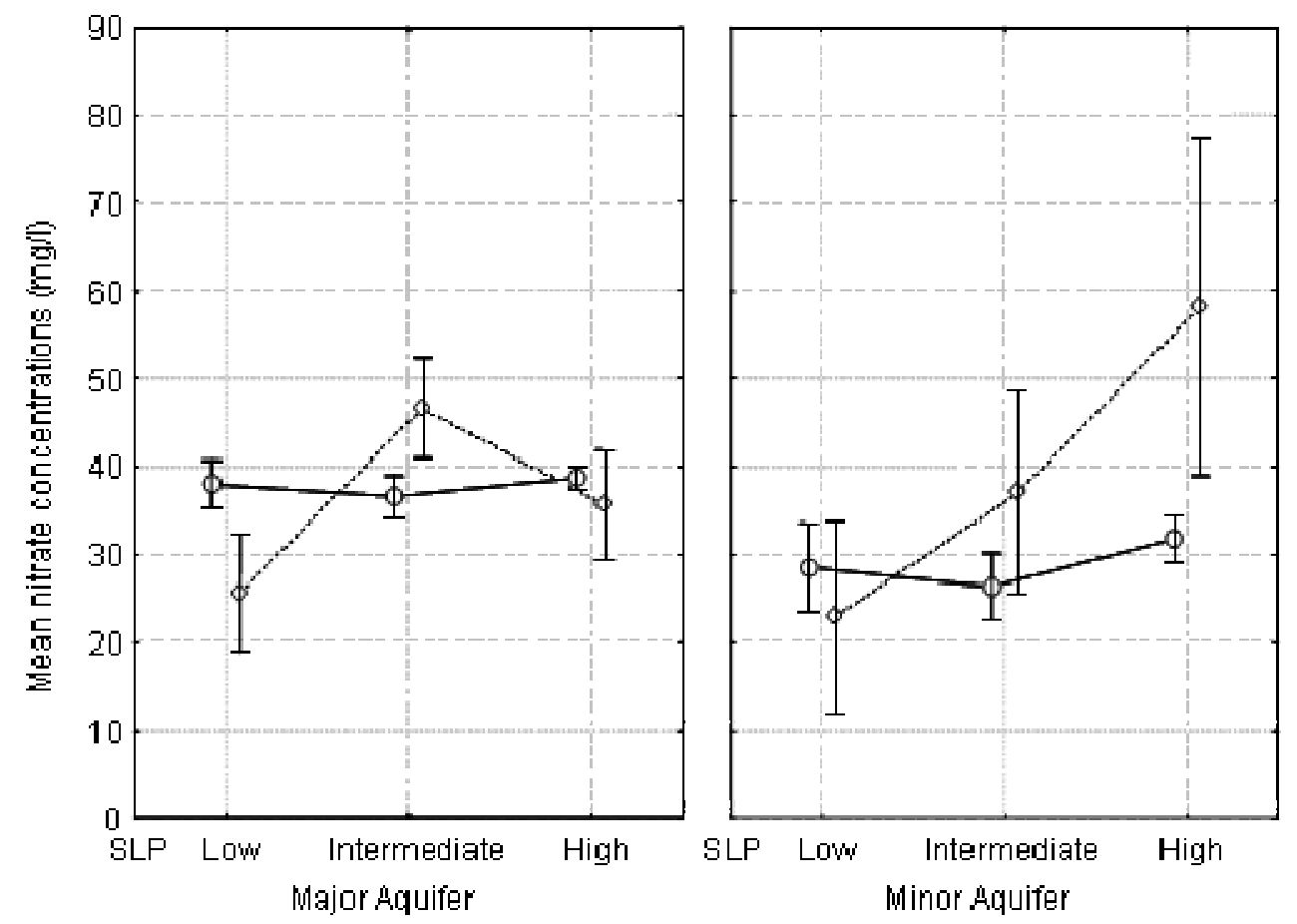

$-\infty$ Drift absent

$-\infty$ Drift present

Figure 5 Results of ANOVA showing the differences between the mean borehole nitrate concentrations for the combinations of aquifer class, presence or absence of low permeability drift and soil-leaching potential (SLP) class 


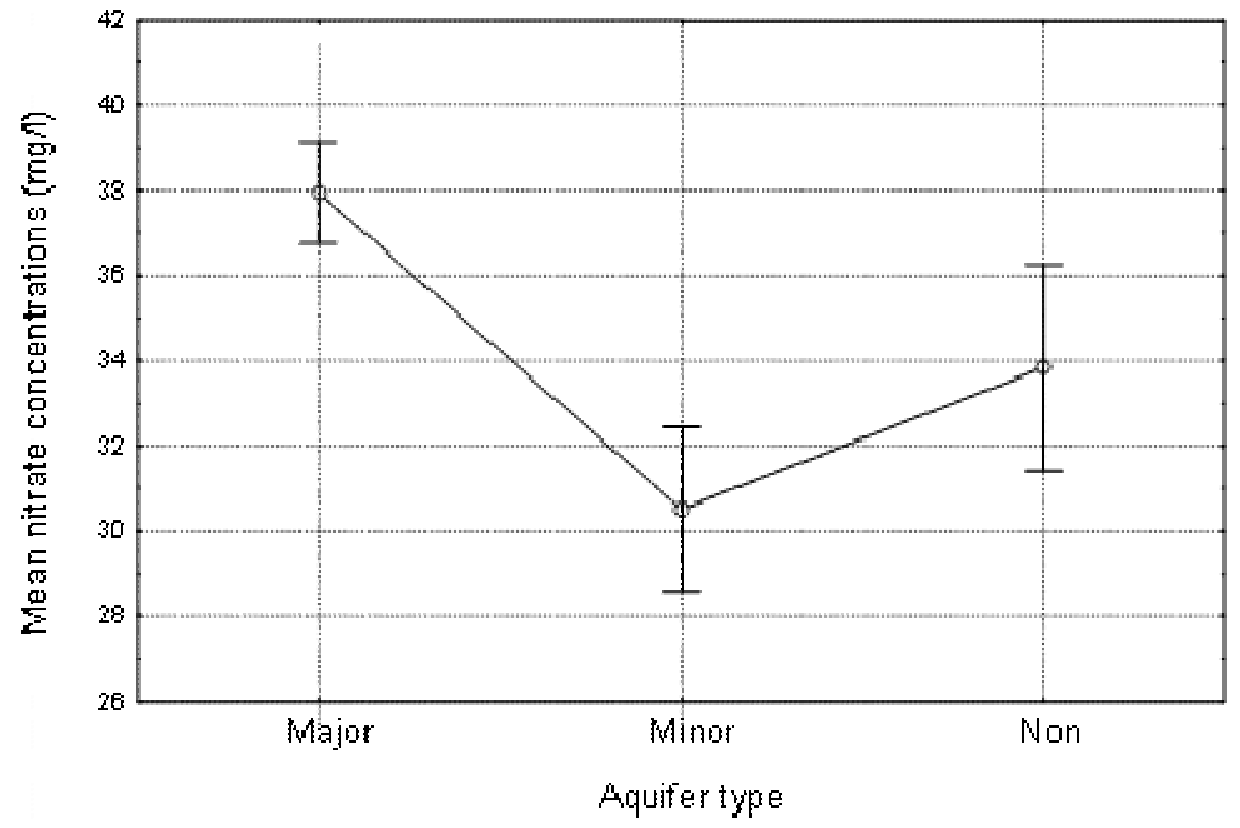

Figure 6 Results of ANCOVA showing the differences between the mean borehole nitrate concentrations for the aquifer classes 